\title{
Functional Dyspepsia: Review of Pathophysiology and Treatment
}

\author{
Nilce Mitiko Matsuda ${ }^{*}, 1,2$, Eduardo Kinoshita ${ }^{1}$, Márcio Eduardo Rautchum Vong ${ }^{1}$, \\ Rafael Delphino dos Santos ${ }^{1}$, Ingrid de Almeida Botacin ${ }^{1}$ and \\ Luis Ernesto de Almeida Troncon ${ }^{3}$
}

\author{
${ }^{I}$ Faculdade de Medicina, Universidade Mogi das Cruzes, Mogi das Cruzes (SP), Brazil \\ ${ }^{2}$ Departamento de Cirurgia e Anatomia, ${ }^{3}$ Departamento de Clínica Médica, Faculdade de Medicina de Ribeirão Preto, \\ Universidade de São Paulo, Ribeirão Preto (SP), Brazil
}

\begin{abstract}
Functional dyspepsia is a very common gastrointestinal disorder observed in the general population, in general outpatient clinic and clinical specialty. It is associated with several treatments, hospitalization, prescription and use of several drugs. Moreover, it is related to self medication, absenteeism and also loss of productivity. The objective of this review is to summarize the pathophysiological mechanisms and the treatment of functional dyspepsia.
\end{abstract}

Keywords: Functional dyspepsia, epigastric pain, early satiation, postprandial fullness, epigastric burning, Helicobacter pylori.

\section{INTRODUCTION}

Dyspepsia is defined as chronic or recurrent pain or discomfort centered in the upper abdomen. Discomfort is defined as a subjective negative feeling that is non-painful, and is considered to incorporate a variety of symptoms, including early satiety, bloating, upper abdominal fullness, or nausea. Dyspepsia can be associated with several conditions such as functional dyspepsia, gastroesophageal reflux disease, gastroduodenal ulcerous disease and cancer [1-3].

Functional dyspepsia is a heterogeneous disorder characterized by relapsing and remitting symptoms, in the absence of any organic, systemic, or metabolic disease that is likely to explain the symptoms [1-3]. The diagnosis of functional dyspepsia or non-ulcerative dyspeptic syndrome is generally used when a full assessment in a patient with dyspepsia fails to identify the cause for their symptoms [13].

Although several definitions are used to describe the symptoms, according to the Rome III consensus, functional dyspepsia was redefined as the presence of epigastric pain or burning, postprandial fullness or early satiation - in the absence of underlying organic disease - whose mechanism is still unknown and treatment is not fully established $[1,4]$.

Functional dyspepsia is a very common gastrointestinal disorder observed in the general population, in the general outpatient clinics and also in the clinical specialty [1-4]. Functional dyspepsia is associated with several treatments, hospitalization, prescription and use of several drugs [1-3]. And it is related to self medication, absenteeism and also loss of productivity [1-3]. Since functional dyspepsia is a

*Address correspondence to this author at the Departamento de Cirurgia e Anatomia, Faculdade de Medicina de Ribeirão Preto, Universidade de São Paulo; Av. Bandeirantes 3900, Ribeirão Preto, SP, 14049-900, Brazil; Tel/Fax: 55-16-3633-0836;

E-mails: nmmatsuda@uol.com.br,nmatsuda@zipmail.com.br very common gastrointestinal disorder observed in the general population, the purpose of this review is to summarize the pathophysiology and the treatment of functional dyspepsia.

\section{DISCUSSION}

Pathophysiological mechanisms currently deemed to be involved in functional dyspepsia include delayed gastric emptying, impaired gastric accommodation to a meal, hypersensitivity to gastric distention, altered duodenal sensitivity to lipids or acid, abnormal duodenojejunal motility, genetic susceptibility, Helicobacter pylori $(H$. pylori) infections, acute gastrointestinal infections, neurohormonal dysfunction, autonomic dysfunction, psychosocial factors and stress (Table 1) [1-9].

\section{Table 1. Pathophysiological Mechanisms Related to Functional Dyspepsia}

\begin{tabular}{|l|}
\hline Delayed gastric emptying \\
\hline Impaired gastric accommodation to a meal \\
\hline Hypersensitivity to gastric distention \\
\hline Altered duodenal sensitivity to lipids or acid \\
\hline Abnormal duodenojejunal motility \\
\hline Genetic susceptibility \\
\hline Helicobacter pylori infection \\
\hline Acute gastrointestinal infection \\
\hline Neurohormonal dysfunction \\
\hline Autonomic dysfunction \\
\hline Psychosocial factor \\
\hline Stress \\
\hline
\end{tabular}

Functional dyspepsia is a highly prevalent and heterogeneous disorder characterized by relapsing and 
remitting symptoms; though the pathophysiological mechanism is not completely clear, gender-related differences were observed in several studies $[1-5,9,10]$. Some investigations have shown that gender-related differences have been observed in some studies of both the prevalence of individual dyspepsia symptoms, and in gastric emptying and proximal gastric motor function $[5,7,10,11]$.

Gender differences also appear to be present in the psychosocial domain, with dyspeptic women experiencing a lesser sense of well-being, as well as an association of an abuse history with functional dyspepsia [5-7]. Though the pathophysiological mechanisms are not clear, some specific features related to gender in functional dyspepsia and the effect of gender in the mechanism of functional dyspepsia are an area of growing interest and several studies $[1-5,10]$.

Idiopathic gastroparesis or primary delayed gastric emptying is a condition in which a delay occurs in the gastric emptying without any mechanical obstruction $[4,12,13]$. This condition can be found in up to $30 \%$ of patients with diagnosis of functional dyspepsia and can contribute to the symptoms [12, 13]. Although the pro-kinetic drugs are effective in improving the motor function, there is an inconsistent relationship between changes in the motor functions and improvement of the symptoms in functional dyspepsia $[2,3,9,12,13]$.

The role of infection by $H$. pylori in the pathophysiology of symptoms in functional dyspepsia is not very clear yet; however, despite some controversial studies, some authors have recommended prescribing drugs for $H$. pylori eradication in patients with dyspepsia even in the absence of symptoms of alarms $[6,8,14]$.

Though several epidemiological studies suggest an increased incidence of infection by $H$. pylori in developing countries, there appears to be no statistical difference regarding improvements of symptoms of dyspepsia after eradication of H. pylori [15].

Therefore no specific treatment has been established for functional dyspepsia and several drugs aimed to alleviate the symptoms have been employed, such as removal of acid secretion, pro-kinetic drugs, eradication of $H$. pylori, and antidepressants (Table 2) [2, 3, 6, 8, 9, 14].

Table 2. Drug Treatment of Functional Dyspepsia

\begin{tabular}{|l|}
\hline Removal of acid secretion \\
\hline Pro-kinetic drugs \\
\hline Eradication of Helicobacter pylori \\
\hline Antidepressants \\
\hline
\end{tabular}

\section{CONCLUSION}

Functional dyspepsia is a common gastrointestinal disorder observed in the general population, in general outpatient clinic and clinical specialty. Although the pathophysiological mechanisms and causes are not fully established, there seems to be some specific features related to gender in functional dyspepsia. Despite of idiopathic gastroparesis or primary delayed gastric emptying can be found in functional dyspepsia pro-kinetic drugs seem to improve the motor disorders but not the symptoms. Even though some epidemiological studies suggest an increased incidence of infection by $H$. pylori in developing countries, there appears to be no statistical difference regarding improvements of symptoms of dyspepsia after eradication of $H$. pylori.

\section{ACKNOWLEDGEMENT}

This work is supported by a grant from Fundação de Amparo a Pesquisas do Estado de São Paulo (FAPESP 2006/50084-2) and a grant from Conselho Nacional de Desenvolvimento Científico e Tecnológico (CNPq 474531/2008-2).

\section{REFERENCES}

[1] Drossman DA. The functional gastrointestinal disorders and the Rome III process. Gastroenterology 2006; 130: 1377-90.

[2] Suzuki H, Nishizawa T, Hibi T. Therapeutic strategies for functional dyspepsia and the introduction of the Rome III classification. J Gastroenterol 2006; 41: 513-23.

[3] Tack J, Lee KJ. Pathophysiology and treatment of functional dyspepsia. J Clin Gastroenterol 2005; 39: 211-6.

[4] Tack J, Talley NJ, Camilleri M, et al. Functional gastroduodenal disorders. Gastroenterology 2006; 130: 1466-79.

[5] Flier SN, Rose S. Is functional dyspepsia of particular concern in women? A review of gender differences in epidemiology, pathophysiologic mechanisms, clinical presentation, and management. Am J Gastroenterol 2006; 101: 644-53.

[6] Mearin F, de Ribot X, Balboa A, et al. Does Helicobacter pylori infection increase gastric sensitivity in functional dyspepsia? Gut 1995; 37: 47-51.

[7] Mizuta Y, Shikuwa S, Isomoto $\mathrm{H}$, et al. Recent insights into digestive motility in functional dyspepsia. J Gastroenterol 2006; 41: $1025-40$.

[8] Perri F, Clemente R, Festa V, et al. Patterns of symptoms in functional dyspepsia: role of helicobacter pylori infection and delayed gastric emptying. Am J Gastroenterol 1998; 93: 2082-8.

[9] Tack J, Kindt S. Pathogenesis and therapy for idiopathic dyspepsia. Curr Gastroenterol Rep 2005; 7: 437-44.

[10] Lorena SL, Tinois E, Brunetto SQ, et al. Gastric emptying and intragastric distribution of a solid meal in functional dyspepsia: influence of gender and anxiety. J Clin Gastroenterol 2004; 38 : 230-6.

[11] Mearin F, Balboa A, Zarate N, et al. Placebo in functional dyspepsia: symptomatic, gastrointestinal motor, and gastric sensorial responses. Am J Gastroenterol 1999; 94: 116-25.

[12] Kindt S, Tack J. Impaired gastric accommodation and its role in dyspepsia. Gut 2006; 55: 1685-91.

[13] Tack J, Bisschops R, Sarnelli G. Pathophysiology and treatment of functional dyspepsia. Gastroenterology 2004; 127: 1239-55.

[14] Suzuki H, Masaoka T, Sakai G, Ishii H, Hibi T. Improvement of gastrointestinal quality of life scores in cases of Helicobacter pylori-positive functional dyspepsia after successful eradication therapy. J Gastroenterol Hepatol 2005; 20: 1652-60.

[15] Mazzoleni LE, Sander GB, Ott EA, et al. Clinical outcomes of eradication of Helicobacter pylori in nonulcer dyspepsia in a population with a high prevalence of infection: results of a 12month randomized, double blind, placebo-controlled study. Dig Dis Sci 2006; 51: 89-98. 